\title{
Virtuous laughter: we should teach medical learners the art of humor
}

\author{
Simon Oczkowski
}

\begin{abstract}
There is increasing recognition of the stress and burnout suffered by critical care workers. Physicians have a responsibility to teach learners the skills required not only to treat patients, but to cope with the demands of a stressful profession. Humor has been neglected as a strategy to help learners develop into virtuous and resilient physicians. Humor can be used to reduce stress, address fears, and to create effective health care teams. However, there are forms of humor which can be hurtful or discriminatory. In order to maximize the benefits of humor and to reduce its harms, we need to teach and model the effective and virtuous use of humor in the intensive care unit.
\end{abstract}

Medicine is a noble profession, and so physicians are expected to demonstrate virtuous character. In the hospital, we teach medical students and residents the knowledge, skills, and attitudes required to treat the critically ill. They learn how to comfort patients and their families during times of great suffering. Generally, we are good at teaching these skills. But increasingly, evidence shows that ICU workers have a high rate of burnout and job dissatisfaction [1,2]. We need to teach our learners not only how to care for the sick, but also how to care for themselves. We need to create novel methods for developing virtuous physicians, and at the same time we need to make the ICU a more humane environment for those who work there. And for that reason, I think it is time we begin to teach medical learners the art of humor.

It may at first seem morbid, but humor is one of the reasons I look forward to my work in critical care. Sharing laughs with patients, families, and staff is one of the

Correspondence: oczkowsj@mcmaster.ca

Hamilton General Hospital, McMaster Clinic, 4th floor, Room 434, 237 Barton St East, Hamilton, ON L8L 2X2, Canada 
care. Humor can cultivate the virtues of humility and compassion.

But the use of humor in medicine has associated risks, as well as benefits. Jokes which poke fun at vulnerable patients, or which are discriminatory - laced with racism, sexism, or other cruel prejudices - are harmful. Just as humor can bring us together, it can be used to exclude and depersonalize others. It can deprive people of the respect they deserve. Inappropriate humor can do this whether these jokes are heard by patients and their families, or shared behind closed doors. Levity can also distract us from the seriousness of the situation. We are charged with the care of the critically ill, and we cannot be flippant in our delivery of the best possible care. For us, the ICU is the place where we live and work, day after day. For the patients and families, it is the place they dread coming to, night after night. We need to show understanding and respect for their plight. We need to demonstrate the virtues of temperance and self-reflection in our use of humor. We must avoid taking pleasure in the suffering of others.

\section{Conclusion}

It is time we make a serious effort to teach medical students and residents the art of virtuous humor. Critics might say that curriculum space is too limited to dedicate time to jokes. Others may claim that developing virtues is outside the scope of the medical curriculum. I would argue, however, that such teaching need not be formal - we should teach virtuous humor by example. We can make jokes to keep our spirits up; to acknowledge our fears; and to create camaraderie. Just as importantly, we need to be role models for professionalism. Our jokes need to be rooted in ironic situations, clever word-play, and in our own flaws - jibes should not at the expense of the people we care for. We need to take the job seriously - but take ourselves in good humor.

\section{Competing interests}

The author declares that he has no competing interests.

Author's information

$\mathrm{SO}$ is a clinical scholar in the division of critical care at McMaster University, Canada.

\section{Acknowledgments}

Thank you to Doug Gowans and Michael Szego at the University of Toronto for their review and editing of the manuscript.

Published online: 11 May 2015

\section{References}

1. Embriaco N, Papazian L, Kentish-Barnes N, Pochard F, Azoulay E. Burnout syndrome among critical care healthcare workers. Curr Opin Crit Care. 2007;13:482-8.
2. Mason VM, Leslie G, Clark K, Lyons P, Walke E, Butler C. Compassion fatigue, moral distress, and work engagement in surgical intensive care unit trauma nurses: a pilot study. Dimens Crit Care Nurs. 2014;33:215-25.

3. Leiber DB. Laughter and humor in critical care. Dimens Crit Care Nurs. 1986;5:162-70.

4. Dean RAK, Major JE. From critical care to comfort care: the sustaining value of humor. J Clin Nurs. 2008;17:1088-95. 